\title{
Unlocking the power of the host response to improve the management of infectious diseases
}

\author{
Kfir Oved ${ }^{*, 1}$, Eran Eden ${ }^{1}$ \& Tanya M Gottlieb**,1 \\ ${ }^{1}$ MeMed, 5 Nahum Het Street, Haifa, Israel \\ *Author for correspondence: kfiroved@me-med.com \\ **Author for correspondence: tanya.gottlieb@me-med.com
}

\section{"The fundamental value of a diagnostic or prognostic test lies in its ability to accurately and clearly guide patient treatment and improve health outcomes"}

First draft submitted: 3 June 2019; Accepted for publication: 28 November 2019; Published online: 18 December 2019

Keywords: actionable infectious disease tests $\bullet$ antimicrobial resistance $\bullet$ bacterial versus viral diagnostic $\bullet$ CRP $\bullet$ host biomarker $\bullet$ immune-protein signature $\bullet$ IP-10 • point-of-care platform $\bullet$ sepsis $\bullet$ TRAIL

\section{Need: improved actionability for tests used to manage infection}

The fundamental value of a diagnostic or prognostic test lies in its ability to accurately and clearly guide patient treatment and improve health outcomes. In the case of an acute infection, this actionability demands fulfillment of a few unique requirements. First, the test results must be available within minutes, especially in the outpatient settings where the patient journey is very short. Second, the test must overcome the challenge of 'false' findings due to colonization and carriage of 'bystander' microbes that are not related to the acute infection itself (e.g., group A streptococcus carriage). Today, the actionability of most pathogen detection tests is limited not only by prolonged time to results and false findings, but also by two additional constraints. First, pathogen detection requires access to the infection site, which in roughly $25 \%$ of infections is impractical or impossible [1]; for example, to access the lower airways in pneumonia or inner ear in acute otitis media. Second, the rapid genomic and antigenic changes of many pathogens negatively impact test performance (e.g., influenza).

The need for improved actionability when managing patients with acute infection is driving attempts to develop new tests that leverage our immune response as opposed to detecting the pathogen. This is because host responsebased tests have the potential to overcome the aforementioned constraints. Host biomarkers, specifically proteins, can be rapidly measured without complex sample preparations or any requirement to grow the pathogen. Notably, our immune system is largely inert to colonizers as long as these do not invade our tissues, which means that hostbased tests exhibit fewer false findings. Furthermore, as our immune responses can be measured in the circulation, their evaluation does not require access to the infection site. Last, the human immune system is the product of a long evolutionary process of identifying and responding to variable and invariable pathogenic motifs, so immune detection of emerging pathogens is fairly robust.

\section{Potential solution: host response-based signatures}

A fundamental clinical dilemma in infectious disease is the decision whether to treat, or not to treat, with antibiotics a patient that is presenting with symptoms of acute infection. The diagnostic uncertainty drives physicians to both over and under utilize antibiotics and antivirals ('just in case' vs 'watchful waiting', respectively), which may not only be detrimental to the individual outcome, but also contributes to antimicrobial resistance, one of the greatest healthcare challenges of our time [2]. Despite being a widely accepted unmet clinical need, and the numerous efforts to find solutions, the accuracy in making this decision has not significantly improved over the last few decades. For the vast majority of acute infections, especially in the outpatient setting, the clinician needs primarily to differentiate bacterial from viral etiology in order to decide how to manage the patient. Even in the minority of cases where pathogen-specific information is required, the prior knowledge of whether the infection is bacterial or

Future Medicine 
viral can improve the early empiric treatment and focus the diagnostic workup. A host-response based test has the potential to provide actionable triage in a rapid, accurate and affordable manner.

There are several reports describing promising combinations of host RNAs that appear to discriminate between bacterial and viral infection [3]. However, measurement of multiple host RNAs both rapidly (within minutes) and quantitatively remains a significant technical challenge. This technological hurdle, long time to results, as well as cost, currently prohibits host-RNA based infectious disease applications from being widely applied within the workflow, especially in the outpatient settings. Circulating host proteins are an attractive alternative as they can be rapidly measured (minutes) at the point-of-care using well established, cost-effective technologies. Single protein host biomarkers like PCT and CRP [4] are routinely used. However, as for all individual markers, these tests exhibit variability between patients and are sensitive to time from symptom onset, clinical syndrome and pathogen species and therefore are characterized by limited accuracy [5,6].

To address the performance limitation of single biomarkers, predictive scores have been developed that combine multiple protein markers with blood count parameters [7-11]. Yet, these combinations typically demonstrate minor diagnostic improvement over individual markers, likely due to the incorporation of predominantly bacterialinduced markers (e.g., ANC, PCT, IL-6, IL-8, serum amyloid A, CRP and sTREM), which share common biological pathways. Recently, a host signature that combines unrelated host proteins participating in different pathways has been developed and independently validated [12-14]. Its reported sensitivity and specificity of greater than $90 \%$ for differentiating between bacterial and viral infections and superiority over other routine biomarkers is attributed to the unique combination of viral-induced (TRAIL, IP-10) and bacterial-induced (CRP) biomarkers, such that the participating proteins cover each other's 'blind spots'. As theorized for a host protein-based test, this signature can be measured within minutes, is robust to evolving strains, does not require access to the infection site (e.g., in cases of pneumonia), and has been shown to be inert to the presence of colonizers, and therefore has the potential to significantly improve infectious disease management and antibiotic stewardship [12-14].

Another unmet clinical need in the infectious disease space is the early prediction of sepsis, a life-threatening organ dysfunction caused by a dysregulated host response to infection. Sepsis has a high mortality rate and is the leading cause of death in US hospitals [15]. It has high associated healthcare costs, being the number one in-patient hospital cost and number one cause of hospital re-admissions [16]. Sepsis was and still remains a major diagnostic and prognostic challenge, as both presence of infection and severity of illness need to be rapidly evaluated, which may explain why today's traditional approaches have demonstrated limited utility [17]. Mortality from sepsis increases by as much as $8 \%$ for every hour that treatment is delayed [18]. Host-based approaches have shown the potential to address this complexity and provide actionable information. There are several host-RNA signatures in different stages of development, which require demonstration of clinical validation and utility $[19,20]$. In addition, there are candidate host proteins that show promise as indicators of illness severity [21], which when combined with biomarkers of microbial infection may serve as a tool to rapidly and accurately predict the likelihood of sepsis in patients with acute infection.

Other unmet clinical needs that may be addressed by host-based tests include detection of early infection, which could be critical in preventing disease spread during a public health emergency, and the detection and management of tuberculosis (TB). TB kills more people than any other single infectious disease. Each year, millions of TB infections go undiagnosed and for those with a positive diagnosis, it is not clear who has active contagious TB. A host-protein test based on blood or urine samples (as opposed to sputum) has the potential to serve as a rapid and inexpensive triage test to rule out $\mathrm{TB}$, reducing the burden of the additional workup required to diagnose and monitor contagiousness, as well as drug resistance.

\section{Actionable solution: host signature plus point-of-care platform}

As sample-to-answer time is one of the most challenging limitations in infectious disease management, the use of host response-based tests can make a real impact only if combined with rapid and affordable measurement platforms. Such platforms need to be accurate, user friendly, cost effective, and applicable across the continuum of care, especially in the outpatient and other decentralized settings. To meet these demands and overcome the challenge of measuring TRAIL that can be present in single picomolar concentrations, a new point-of-care diagnostic immunoassay system called MeMed $\mathrm{Key}^{\top \mathrm{TM}}$ has been developed for performing, within 15 min, the test for differentiating between bacterial and viral infection, based on measurement and computational integration of TRAIL/IP-10/CRP [22]. Also, a US FDA cleared laboratory PCR-based test for sepsis that computationally integrates the measurements of four host RNAs (SeptiCyte ${ }^{T M} \mathrm{LAB}$ ) [20] is currently being transitioned onto a 
user-friendly platform that can provide results in $90 \mathrm{~min}$ (Idylla ${ }^{\top M}$ platform). Regulatory clearance, value-based reimbursement models, and adoption along the continuum of care of these and other host-based tests on point-ofcare platforms have the potential to significantly improve infectious disease management, with the ultimate goal of improved patient outcomes.

\section{Financial \& competing interests disclosure}

TM Gottlieb, K Oved and E Eden are employees of MeMed with stock and/or stock options. MeMed discovered and validated a host-protein signature based on TRAIL/IP-10/CRP and is developing a platform to run the test. The authors have no other relevant affiliations or financial involvement with any organization or entity with a financial interest in or financial conflict with the subject matter or materials discussed in the manuscript apart from those disclosed.

No writing assistance was utilized in the production of this manuscript.

\section{Open access}

This work is licensed under the Attribution-NonCommercial-NoDerivatives 4.0 Unported License. To view a copy of this license, visit http://creativecommons.org/licenses/by-nc-nd/4.0/

\section{References}

1. CDC.gov. NAMCS/NHAMCS - NCHS Reports Using Ambulatory Health Care Data. http://www.cdc.gov/nchs/ahcd/ahcd_reports.htm

2. Home. AMR Review. http://amr-review.org/

3. Cohen A, Bont L, Engelhard D et al. A multifaceted "omics" approach for addressing the challenge of antimicrobial resistance. Future Microbiol. 10(3), 365-376 (2015).

4. Limper M, de Kruif MD, Duits AJ, Brandjes DPM, van Gorp ECM. The diagnostic role of Procalcitonin and other biomarkers in discriminating infectious from non-infectious fever. J. Infect. 60(6), 409-416 (2010).

5. Tang BM, Eslick GD, Craig JC, McLean AS. Accuracy of procalcitonin for sepsis diagnosis in critically ill patients: systematic review and meta-analysis. Lancet Infect. Dis. 7(3), 210-217 (2007).

6. van der Meer V, Neven AK, van den Broek PJ, Assendelft WJJ. Diagnostic value of C reactive protein in infections of the lower respiratory tract: systematic review. BMJ 331(7507), 26 (2005).

7. Van den Bruel A, Thompson MJ, Haj-Hassan T et al. Diagnostic value of laboratory tests in identifying serious infections in febrile children: systematic review. BMJ 342, d3082 (2011).

8. Bafadhel M, Clark TW, Reid C et al. Procalcitonin and C-reactive protein in hospitalized adult patients with community-acquired pneumonia or exacerbation of asthma or COPD. Chest 139(6), 1410-1418 (2011).

9. Gibot S, Béné MC, Noel R et al. Combination biomarkers to diagnose sepsis in the critically ill patient. Am. J. Respir. Crit. Care Med. 186(1), 65-71 (2012).

10. Thayyil S, Shenoy M, Hamaluba M, Gupta A, Frater J, Verber IG. Is procalcitonin useful in early diagnosis of serious bacterial infections in children? Acta Paediatr. Oslo Nor. 1992 94(2), 155-158 (2005).

11. Lacour AG, Gervaix A, Zamora SA et al. Procalcitonin, IL-6, IL-8, IL-1 receptor antagonist and C-reactive protein as identificators of serious bacterial infections in children with fever without localising signs. Eur. J. Pediatr. 160(2), 95-100 (2001).

12. Oved $\mathrm{K}$, Cohen A, Boico O et al. A novel host-proteome signature for distinguishing between acute bacterial and viral infections. PLoS ONE 10(3), e0120012 (2015).

13. van Houten $\mathrm{CB}$, de Groot JAH, Klein A et al. A host-protein based assay to differentiate between bacterial and viral infections in preschool children (OPPORTUNITY): a double-blind, multicentre, validation study. Lancet Infect. Dis. 17(4), 431-440 (2016).

14. Srugo I, Klein A, Stein M et al. Validation of a novel assay to distinguish bacterial and viral infections. Pediatrics 140(4), e20163453 (2017).

15. Liu V, Escobar GJ, Greene JD et al. Hospital deaths in patients with sepsis from 2 independent cohorts. JAMA 312(1), 90-92 (2014).

16. Torio CM, Moore BJ. National Inpatient Hospital Costs: The Most Expensive Conditions by Payer, 2013: Statistical Brief \#204. In: Healthcare Cost and Utilization Project (HCUP) Statistical Briefs, Agency for Healthcare Research and Quality (US) Rockville (MD) (2006).

17. Gunsolus IL, Sweeney TE, Liesenfeld O, Ledeboer NA. Diagnosing and managing sepsis by probing the host response to Infection: advances, opportunities, and challenges. J. Clin. Microbiol. 57(7), e00425 (2019).

18. Kumar A, Roberts D, Wood KE et al. Duration of hypotension before initiation of effective antimicrobial therapy is the critical determinant of survival in human septic shock. Crit. Care Med. 34(6), 1589-1596 (2006).

19. Sweeney TE, Azad TD, Donato M et al. Unsupervised analysis of transcriptomics in bacterial sepsis across multiple datasets reveals three robust clusters. Crit. Care Med. 46(6), 915-925 (2018).

20. Miller RR, Lopansri BK, Burke JP et al. Validation of a host response assay, SeptiCyte LAB, for discriminating sepsis from systemic inflammatory response syndrome in the ICU. Am. J. Respir. Crit. Care Med. 198(7), 903-913 (2018). 
21. Oved $\mathrm{K}$, Cohen A, Boico $\mathrm{O}$ et al. Tumor necrosis factor-related apoptosis-inducing ligand protein as a marker for disease severity in patients with acute infection. Open Forum. Infect. Dis. 3(Suppl. 1), S1 (2016).

22. MeMed Diagnostics. MeMed. https://www.me-med.com 